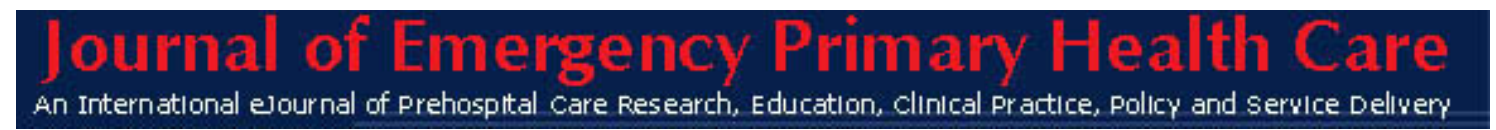

ISSN 1447-4999

\title{
PROFILE
}

Article 990155

\section{Kevin Broadbent - Volunteer Ambulance Officer of the Year 2004, St John Ambulance WA.}

\author{
Rhona Macdonald
}

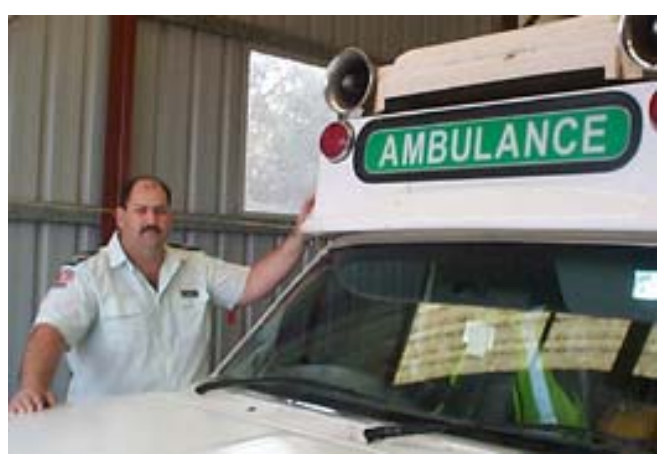

Described by his peers as the epitome of a committed volunteer, Kevin Broadbent of St John Ambulance, Leinster in rural Western Australia (WA), was winner of the St John Volunteer Ambulance Officer of the Year in 2004.

To find out more about the success behind his role as a volunteer, Kevin was interviewed by Rhona Macdonald, Editorial Assistant for JEPHC.

RM: How long have you been involved as a volunteer with St John Ambulance in WA?

KB: I began as a volunteer in Kalgoorlie, (Western Australia) in May 1988 and received my first volunteer qualification - (Grade 1 Officer now known as Primary Care Ambulance Officer) in November 1988.

RM: What is your current level of qualification and what is the highest level you can achieve as a volunteer?

KB: I am currently trained to Advanced Ambulance Care. This is the highest level you can achieve as a volunteer working in remote country areas. I am able to train volunteer ambulance officers and first aid instructors whose skills are used to train the volunteers and members of the local community.

RM: What was your motivation to become involved as a volunteer?

KB: I wanted to be able to assist and help others who were sick and injured. I also wanted to put some time into the community which I see as a necessity.

RM: What is your career outside of your role with St John Ambulance?

KB: I am currently the Emergency Services Coordinator for BHP Billiton - areas of responsibility are managing and coordinating underground and surface mine rescue teams, the Site Ambulance, Fire teams and Airport management. When I started with St John's in 1988, I was a Restricted Open Cut Quarry Manager in Kalgoorlie. My family and I then moved to Norseman and after a year there we relocated to Leinster where we now reside. 
RM: How much of your time is devoted to training and maintaining your skills as a volunteer?

KB: I spend every Tuesday night at the Ambulance Sub - Center training the volunteers and maintaining my skills. I also coordinate regular training exercises involving the local police, ambulance and mine rescue as well as FESA which stands for - Fire \& Emergency Service Authority of Western Australia to keep our skills up to date. It is really hard to place a time on the hours/days that I spend maintaining my current skills, as I also spend time in Perth and Kalgoorlie updating.

RM: How many hours do you normally work as a volunteer throughout the year, or can you be called upon at any given time? Can you provide examples of this?

KB: I can be called upon at any given time, although we have a roster system for all volunteers to be on call, (new volunteers spend the first three months on call as an observer under my watchful eye this is to ensure that the patient receives the best care available, and the volunteer learns without placing themselves in a compromising situation). Depending on the type of call out and the training level of the volunteer on call, I may attend with them to assist where required, and to encourage them in ways which will lead to them obtaining experience and enhancement of their skills. Examples of this are any major trauma or serious medical conditions - heart attack, stroke etc. St John's - Leinster covers an area of 10,000 square kilometers which includes highways, stations and mining leases.

RM: Do you work independently or does your work involve assisting other paramedics, GP’s etc.?

KB: My job as Emergency Services Coordinator requires me to manage all mine site paramedics and volunteer mine rescue medical staff. I also assist local nurses and doctors when required. As a St John Ambulance volunteer I assist the nurse and doctor on occasion as some medical cases require extra assistance or another pair of hands.

\section{RM: Does your work as a volunteer involve the rural and/or metropolitan community?}

KB: Yes, I involve the community of Leinster in fundraising and recruiting of new volunteers. We also call on some of the residents to act as patients in our training sessions.

RM: Can you describe any aspects of your work in the rural community that are culturally significant or different to those experienced by volunteers in the metropolitan community?

KB: I suppose we spend a lot more time with the people in our community, which we can because of its relatively small population. We usually know the person we need to attend, either through our jobs or personally, so we have an attachment and interest in them that metropolitan volunteers may not experience.

\section{RM: What are the most interesting tasks that you have been involved in as a volunteer?}

KB: Where do I start? - Training school kids in first aid and showing the pre-primary school kids through the Ambulance and sub-center so they are not scared if they or someone in their family ever requires an ambulance.

Teaching first aid to the WA Police... Land search and rescues in the outback...Coordination of mock emergencies such as airport disasters... Fundraising for a new ambulance and equipment - we raised $\$ 10,000$ at one function which was a Beer Festival - not sure why this was so successful....

Dealing with patients... I have had to assist in the rescue of a person trapped in an lift shaft, where the fire brigade had to cut the person free... Fortunately the person survived the multiple traumatic injuries that he sustained, and although now in a wheel chair, I believe he has since been successfully rehabilitated back into the work force. 
I also had to assist in the rescue of another person who fell down an abandoned mine shaft. Injuries included multiple fractures of the lower legs and forearm and some minor internal injuries... Only recently I came across this person again when he stopped me in the street to ask if I was the attending ambulance officer on that day. He thanked me for my efforts and I was glad to see that he hadn't suffered any trauma from the event.

RM: So in what ways did you feel you were able to contribute your skills to the care of those patients in such challenging situations?

KB: My knowledge of the mining industry gave me a good understanding on the nature of injuries that they may have sustained prior to us gaining access to them for treatment. My rope rescue skills enabled us to descend down a mine shaft, my level of ambulance officer training enabled me to treat the injuries, apply a MAST (Medical Anti Shock Trousers) suit and administer pain relief until additional medical treatment could be given by the flying doctor and hospital.

RM: What significant changes in your role as a volunteer have been brought about as a result of newer technologies? (E.g. telemedicine, communications etc.)

KB: Mobile and Satellite phones have made communication with other medical professionals more effective.

The introduction of the defibrillator/heart monitor has given us the ability to monitor vital signs more closely.

Introduction and training in the use of an EpiPen, which is a specially which is a specially designed device that resembles a pen and contains epinephrine. It can be a lifesaver when used in the management of anaphylaxis (severe allergic reactions).

Newer ambulance design has also provided us with an improved and more workable area...

RM: Can you describe the most personally rewarding tasks that you have been involved in as a volunteer?

KB: Resuscitation of a close friend's father who had a heart attack while he was visiting... Receiving letters of thanks from patients following their recovery... Undertaking the project of raising enough money to purchase a new mark 4 diesel ambulance for the community in 2002. I have also attended a motor vehicle accident in which my cousin was involved (I had not seen him for 13 years).

RM: So if you could describe the underpinning qualities of a good volunteer, what would they be?

KB: A caring nature, and a drive to assist the sick and injured...being community minded... and a devotion to learning and teaching...

RM: In what ways has your role as a volunteer evolved with experience, for example in levels of professional responsibility, roles in community education etc.?

I was voted in as President of the Leinster sub - center in 1996, and have held that position for 10 years. I have been asked to speak on different topics (snake awareness and snake bite first aid management, why communities require volunteers to function, heat exhaustion and heat stroke due to high temperatures) for organization. I also coordinate the training for all volunteers... and lead the LEMAC Team (Local Emergency Management Advisory Committee).

RM: In what ways is your work as a volunteer, acknowledged by others in the community? 
KB: It has been acknowledged in several ways... Winning local Citizen of the year award (jointly) with all St John ambulance local volunteers in 1996 and as an individual in 2004... being awarded the "Local Hero" award from the Leonora Shire in 2000 - this involved a trip to the Grand Prix in Melbourne!...I also received the St John's commentary award in 1999...I have also received a certificate from the Police Dept for my efforts as a volunteer in ground searches for missing people in the local rural area.... and receiving of my 12 year service medal from St John's.

\section{RM: How do you encourage people in your community to become involved as volunteers with St John Ambulance? Do you have any words of inspiration?}

KB: In Leinster we encourage the school to involve kids as patients in scenarios and training exercises. The kids get a kick out of this as they learn by observation and also get to know their local ambulance officers. As a result, we now have a number of local teenage kids who are interested in becoming St John Ambulance volunteers. We also encourage other incentives, for instance, for mothers of young children to become involved as volunteers by providing child care fees if they are called out for duty. Additionally, to increase their qualifications, courses through St John Ambulance training department are always available and St John Ambulance - Belmont cover the cost of this.

Words of Inspiration? - 'Learn First Aid - Every second counts!’

Postscript:

Over 2,500 volunteers provide country ambulance services in rural and regional WA 24/7, 365 days a year. In the past year alone, St John Ambulance Volunteers gave over 3.25 million hours toward the delivery of ambulance and first aid services to WA communities, and conservative estimates of the value of the work done by St John Ambulance Volunteers totals over $\$ 60$ million annually. 